\title{
Utility of Atrial and Ventricular Cycle Length Variability in Determining the Mechanism of Paroxysmal Supraventricular Tachycardia
}

\author{
THOMAS C. CRAWFORD, M.D., SIDDHARTH MUKERJI, M.D., ERIC GOOD, D.O., \\ AMAN CHUGH, M.D., FRANK BOGUN, M.D., FRANK PELOSI, Jr., M.D., HAKAN ORAL, M.D., \\ FRED MORADY, M.D., and KRIT JONGNARANGSIN, M.D.
}

From the Division of Cardiovascular Medicine, University of Michigan Health System, Ann Arbor, Michigan, USA

\begin{abstract}
Atrial and Ventricular CL in Determining the Mechanism of PSVT. Introduction: No prior studies have systematically investigated the diagnostic value of cycle length $(C L)$ variability in differentiating the mechanism of paroxysmal supraventricular tachycardia (PSVT).

Methods and Results: We studied 173 consecutive patients with PSVT; 86 typical atrioventricular nodal reentrant tachycardia (AVNRT), 11 atypical AVNRT, 47 orthodromic reciprocating tachycardia (ORT), and 29 with atrial tachycardia (AT). Two consecutive atrial cycles that displayed the most $C L$ variability were selected for analysis. One hundred and twenty-six patients $(73 \%)$ had $\geq 15$ msec variability in tachycardia CL. The change in atrial CL predicted the change in subsequent ventricular CL in six of eight patients (75\%) with atypical AVNRT, 18 of 21 patients $(86 \%)$ with AT, in none of 66 patients with typical AVNRT, and in 32 patients with ORT. The change in atrial CL was predicted by the change in preceding ventricular CL in 55 of 66 patients (83\%) with typical AVNRT, no patient with atypical AVNRT, 27 of 31 patients $(87 \%)$ with ORT, and one of 21 patients $(5 \%)$ with AT. The sensitivity, specificity, and positive and negative predictive values of a change in atrial CL predicting the change in ventricular CL for AT or atypical AVNRT were $83 \%, 100 \%, 100 \%$, and $95 \%$, respectively. The corresponding values for the change in atrial CL being predicted by the change in the preceding ventricular CL for typical AVNRT or ORT were $85 \%, 97 \%, 99 \%$, and $65 \%$, respectively.

Conclusion: Tachycardia CL variability $\geq 15 \mathrm{msec}$ is common in PSVT. A change in atrial CL that predicts the change in subsequent ventricular CL strongly favors AT or atypical AVNRT. A change in atrial CL that is predicted by the change in the preceding ventricular CL favors typical AVNRT or ORT. ( $J$ Cardiovasc Electrophysiol, Vol. 18, pp. 698-703, July 2007)
\end{abstract}

electrophysiologic study, tachycardia, supraventricular/mechanism, tachycardia, paroxysmal/diagnosis/physiopathology, tachycardia, supraventricular/diagnosis/physiopathology, catheter ablation

Various tachycardia characteristics and pacing maneuvers are useful for differentiating specific types of paroxysmal supraventricular tachycardia (PSVT). ${ }^{1-10}$ However, the diagnosis of the tachycardia mechanism may be difficult when the tachycardia is nonsustained or repeatedly terminates during pacing maneuvers.

It has been proposed that participation of the atrioventricular node in the reentrant circuit is proven when a change in the His-His cycle length (CL) precedes and predicts the change in atrial CL during tachycardia CL variability, and that atrial tachycardia (AT) is likely if the reverse situation is present. However, the His potential may not be clearly seen during tachycardia. Because the ventricular CL usually is the same as the His-His CL, the pattern of change in atrial and ventricular CLs during CL variability may be of diagnostic value. No prior studies have systematically analyzed the prevalence

\footnotetext{
Address for correspondence: Krit Jongnarangsin, M.D., Department of Internal Medicine, Division of Cardiovascular Medicine, 1500 E. Medical Center Drive, VAMC 111A, Box 2399, Ann Arbor MI 48109, USA. Fax: (734)769-7381; E-mail: kritj@med.umich.edu
}

Manuscript received 17 December 2006; Revised manuscript received 23 February 2007; Accepted for publication 14 March 2007.

doi: $10.1111 / \mathrm{j} .1540-8167.2007 .00860 . \mathrm{x}$ of CL variability during PSVT or the relationships between fluctuations in atrial and ventricular CLs during PSVT.

The purpose of this study was to determine the prevalence of CL variability during PSVT, to characterize in quantitative fashion the relationship between atrial and ventricular CL variability during PSVT, and to determine the diagnostic value of this finding for distinguishing atrioventricular nodal reentrant tachycardia (AVNRT), orthodromic reciprocating tachycardia (ORT), and AT.

\section{Methods}

\section{Study Subjects}

The subjects of this retrospective study were 173 consecutive patients who underwent an electrophysiology procedure and had inducible PSVT at the University of Michigan and Veterans Administration-Ann Arbor Health System. There were 67 men and 106 women; their mean age was $47 \pm 17$ years.

\section{Electrophysiologic Procedures}

After informed consent, electrophysiologic tests were performed using standard techniques. ${ }^{8}$ Therapy with antiarrhythmic drugs was discontinued at least five half-lives before 
the procedures. The intracardiac electrograms were filtered at $30-500 \mathrm{~Hz}$. The recordings were digitized and stored on optical disks using an EP Workmate recording system (EP Medical Systems, Mt. Arlington, NJ, USA). Overdrive atrial and ventricular pacing and premature extrastimuli were used to induce supraventricular tachycardia. Isoproterenol was infused at a rate of $2-4 \mathrm{mcg} / \mathrm{min}$ if PSVT was nonsustained or noninducible at baseline. The mechanism of PSVT was determined using standard criteria. ${ }^{1,2,6,11-16}$ There were 86 patients with typical AVNRT, 11 with atypical AVNRT, 47 with ORT, and 29 with AT.

\section{Analysis of Cycle Length Variability}

All CL variability measurements were performed off-line in blinded fashion. The entire stored recording of each patient was reviewed and all tachycardias with a confirmed mechanism were analyzed for tachycardia CL variability. To exclude minor fluctuations that were within the measurement error of tachycardia CL, CL variability in this study was defined as a change of at least $15 \mathrm{msec}$ between consecutive atrial cycles. The two consecutive atrial cycles that exhibited the greatest variability were selected for analysis and were designated as $\mathrm{A} 1-\mathrm{A} 2$ and $\mathrm{A} 2-\mathrm{A} 3$. The corresponding $\mathrm{HBE}$ ventricular cycles were designated as V0-V1, V1-V2, and V2-V3 (Fig. 1). The absolute change between atrial and subsequent ventricu$\operatorname{lar} \mathrm{CLs}(\triangle \mathrm{A} 1 \mathrm{~A} 2-\mathrm{V} 1 \mathrm{~V} 2, \Delta \mathrm{A} 2 \mathrm{~A} 3-\mathrm{V} 2 \mathrm{~V} 3)$ and between atrial and preceding ventricular CLs $(\triangle \mathrm{V} 0 \mathrm{~V} 1-\mathrm{A} 1 \mathrm{~A} 2, \Delta \mathrm{V} 1 \mathrm{~V} 2-$
A2A3) were calculated from the following formulas: |V1V2A1A2|, |V2V3-A2A3|, |A1A2-V0V1|, and |A2A3-V1V2|, respectively.

\section{Relationship Between the Changes in Atrial and Ventricular CLS}

The average absolute change between $\triangle \mathrm{A} 1 \mathrm{~A} 2-\mathrm{V} 1 \mathrm{~V} 2$ and $\triangle \mathrm{A} 2 \mathrm{~A} 3-\mathrm{V} 2 \mathrm{~V} 3(\triangle \mathrm{AA}-\mathrm{VV})$ was compared with the average between $\triangle \mathrm{V} 0 \mathrm{~V} 1-\mathrm{A} 1 \mathrm{~A} 2$ and $\triangle \mathrm{V} 1 \mathrm{~V} 2-\mathrm{A} 2 \mathrm{~A} 3(\Delta \mathrm{VV}-$ AA) (Fig. 1). We considered that $\Delta \mathrm{AA}-\mathrm{VV}$ and $\Delta \mathrm{VV}-\mathrm{AA}$ were significantly different if they differed at least $5 \mathrm{msec}$. The relationship between $\Delta \mathrm{AA}-\mathrm{VV}$ and $\triangle \mathrm{VV}-\mathrm{AA}$ was categorized into three groups: (1) the change in the atrial CL predicted the change in subsequent ventricular $\mathrm{CL}$ when $\triangle \mathrm{AA}-$ $\mathrm{VV}$ was less than $\triangle \mathrm{VV}-\mathrm{AA},(2)$ the change in the atrial CL was predicted by the change in the preceding ventricular $\mathrm{CL}$ when $\triangle \mathrm{AA}-\mathrm{VV}$ was greater than $\triangle \mathrm{VV}-\mathrm{AA}$, (3) the relationship was indeterminate when $\triangle \mathrm{AA}-\mathrm{VV}$ and $\triangle \mathrm{VV}-\mathrm{AA}$ were not significantly different.

\section{Statistical Analysis}

Continuous variables are expressed as mean \pm 1 standard deviation and were compared by one-way analysis of variance. Nominal values were compared by chi-square analysis. A P value $<0.05$ was considered significant.
Figure 1. Examples of a change in atrial $C L$ that predicts the change in subsequent ventricular CL. A: Tachycardia $C L$ variability in $A T$ with an atrial $C L$ change ( $\triangle A 1 A 2-$ $A 2 A 3)$ of $60 \mathrm{msec}$. Shown are surface leads $I, I I, I I I$, and VI, and intracardiac recordings from the right atrium (RA), His bundle (HIS) and coronary sinus (CS). The absolute change between A1-A2 and V1-V2 ( $\triangle A 1 A 2-V 1 V 2)$ is 4 msec (|385-389|) and between $A 2-A 3$ and V2-V3 $(\triangle A 2 A 3-V 2 V 3)$ is $2 \mathrm{msec}(\mid 447-$ 449|). The average absolute change between $\triangle A 1 A 2-V 1 V 2$ and $\triangle A 2 A 3-V 2 V 3(\triangle A A-V V)$ is $3 \mathrm{msec}$. The absolute change between $\mathrm{VO}$ $V 1$ and A1-A2 ( $\triangle V O V 1-A 1 A 2)$ is $43 \mathrm{msec}$ (|389-432|) and between $V 1-V 2$ and $A 2-A 3$ ( $\triangle V 1 V 2-A 2 A 3)$ is $64 \mathrm{msec}(|449-385|)$. The average absolute change between $\triangle V O V 1-$ $A 1 A 2$ and $\triangle V 1 V 2-A 2 A 3(\triangle V V-A A)$ is 53.5 msec. $\triangle V V-A A$ is greater than $\triangle A A-V V$, indicating that a change in atrial $C L$ predicts the change in subsequent ventricular $C L B$ : Tachycardia $C L$ variability in atypical AVNRT, with a $\triangle A 1 A 2-A 2 A 3$ of 109 msec. Shown are surface leads I, II, III and VI, and intracardiac recordings from the right atrium (RA), His bundle (HIS), and right ventricle $(R V) . \triangle A 1 A 2-V 1 V 2$ and $\triangle A 2 A 3-V 2 V 3$ are 9 msec and $12 \mathrm{msec}$, respectively, and $\triangle A A-$ $V V$ is $10.5 \mathrm{msec} . \triangle V 0 V 1-A 1 A 2$ and $\triangle V 1 V 2$ $A 2 A 3$ are $86 \mathrm{msec}$ and $100 \mathrm{msec}$, respectively, and $\triangle V V-A A$ is $93 \mathrm{msec}$.
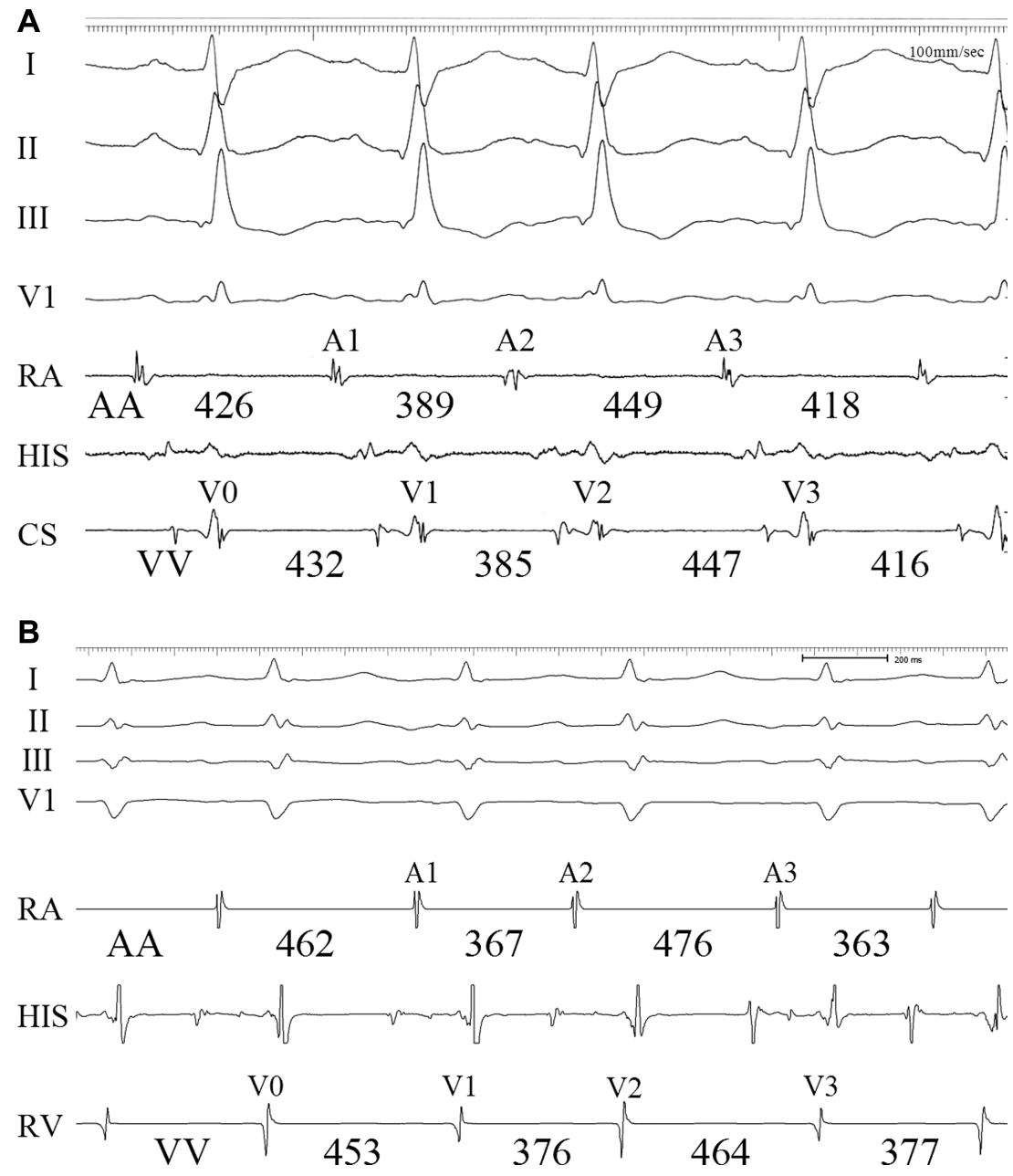
TABLE 1

Supraventricular Tachycardia Characteristics

\begin{tabular}{|c|c|c|c|c|c|c|c|c|c|c|c|c|c|}
\hline & $\begin{array}{c}\mathbf{N} \\
(\mathbf{1 2 7})\end{array}$ & $\begin{array}{l}\text { A1-A2 } \\
\text { (msec) }\end{array}$ & $\begin{array}{c}\text { A2-A3 } \\
(\mathrm{msec})\end{array}$ & $\begin{array}{c}\Delta \text { A1A2- } \\
\text { A2A3 } \\
\text { (msec) }\end{array}$ & $\begin{array}{l}\text { V0-V1 } \\
\text { (msec) }\end{array}$ & $\begin{array}{l}\text { V1-V2 } \\
\text { (msec) }\end{array}$ & $\begin{array}{l}\text { V2-V3 } \\
\text { (msec) }\end{array}$ & $\begin{array}{c}\Delta \text { A1A2- } \\
\text { V1V2 } \\
\text { (msec) }\end{array}$ & $\begin{array}{c}\Delta \text { A2A3- } \\
\text { V2V3 } \\
\text { (msec) }\end{array}$ & $\begin{array}{c}\Delta \mathrm{AA}- \\
\mathbf{V V} \\
(\mathrm{msec})\end{array}$ & $\begin{array}{c}\Delta \text { VOV1- } \\
\text { A1A2 } \\
\text { (msec) }\end{array}$ & $\begin{array}{c}\Delta \text { V1V2- } \\
\text { A2A3 } \\
\text { (msec) }\end{array}$ & $\begin{array}{c}\Delta V V- \\
\text { AA } \\
(\mathbf{m s e c})\end{array}$ \\
\hline $\begin{array}{l}\text { Typical } \\
\text { AVNRT }\end{array}$ & 66 & $361 \pm 73$ & $4 \pm 77$ & & $359 \pm 75$ & $354 \pm 77$ & $352=$ & & & & & & $8 \pm 7$ \\
\hline $\begin{array}{l}\text { Atypical } \\
\text { AVNRT }\end{array}$ & 8 & $391 \pm 93$ & $385 \pm 69$ & $39 \pm 23$ & $380 \pm 72$ & $387 \pm 79$ & $384 \pm 70$ & $17 \pm 18$ & $11 \pm 7$ & $14 \pm 9$ & $33 \pm 32$ & $22 \pm 20$ & $28 \pm 15$ \\
\hline ORT & & & & & & & & $26 \pm$ & $12=$ & & & & $5 \pm 4$ \\
\hline $\mathrm{AT}$ & 21 & & & $8 \pm 17$ & & & & $15 \pm 16$ & $7 \pm 6$ & & $49 \pm 38$ & $25 \pm 16$ & $37 \pm 20$ \\
\hline
\end{tabular}

\section{Results}

The mean CLs of the typical AVNRTs, atypical AVNRTs, ORTs, and ATs were $347 \pm 62,383 \pm 62,325 \pm 40$, and 393 $\pm 67 \mathrm{msec}$, respectively. One of the 47 accessory pathways demonstrated decremental retrograde conduction.

Overall, 126 of 173 patients $(73 \%)$ displayed tachycardia CL variability $\geq 15 \mathrm{msec}$. The prevalence of CL variability was $77 \%$ among the typical AVNRTs, 73\% among the atypical AVNRTs, 66\% among the ORTs, and 72\% among the ATs $(\mathrm{P}=0.617)$. The mean atrial $\mathrm{CL}$ change $(\triangle \mathrm{A} 1 \mathrm{~A} 2-\mathrm{A} 2 \mathrm{~A} 3)$ was $36 \pm 31 \mathrm{msec}$ in the typical AVNRTs, $39 \pm 23 \mathrm{msec}$ in the atypical AVNRTs, $28 \pm 14 \mathrm{msec}$ in the ORTs, and $38 \pm 17$ msec in the ATs $(\mathrm{P}=0.337)$. Means of atrial CLs $(\mathrm{A} 1-\mathrm{A} 2$, A2-A3), ventricular CLs (V0-V1, V1-V2, V2-V3), absolute values of percent change between atrial and subsequent ventricular CLs ( $\triangle \mathrm{A} 1 \mathrm{~A} 2-\mathrm{V} 1 \mathrm{~V} 2, \Delta \mathrm{A} 2 \mathrm{~A} 3-\mathrm{V} 2 \mathrm{~V} 3)$ and between atrial and preceding ventricular CLs ( $\triangle \mathrm{V} 0 \mathrm{~V} 1-\mathrm{A} 1 \mathrm{~A} 2$, $\triangle \mathrm{V} 1 \mathrm{~V} 2-\mathrm{A} 2 \mathrm{~A} 3)$, and the average of absolute values of percent change ( $\triangle \mathrm{AA}-\mathrm{VV}, \triangle \mathrm{VV}-\mathrm{AA})$ for each type of PSVT are shown in Table 1.

Among 126 patients with PSVTs that displayed CL variability, the change in atrial CL predicted the change in subsequent ventricular CL in 24 patients (19\%) (six atypical AVNRTs and 18 ATs) and the change in the atrial CL was predicted by the change in preceding ventricular CL in 83 patients (66\%) (55 typical AVNRs, 27 ORTs, and one AT). The relationship between the change in atrial CL and ventricular CL was indeterminate in 19 of 126 (15\%) patients (11 typical AVNRTs, two atypical AVNRTs, four ORTs, and two ATs). The prevalences of the change in atrial CL predicting the change in subsequent ventricular CL, the change in the atrial CL being predicted by the change in preceding ventricular CL, and an indeterminate relationship in each type of PSVT are shown in Table 2.

The sensitivity, specificity, positive predictive value, and negative predictive value of atrial CL predicting subsequent

TABLE 2

Relationship Between Atrial and Ventricular Cycle Lengths

\begin{tabular}{lccc}
\hline & $\begin{array}{c}\text { Atrial CL } \\
\text { Predicting } \\
\text { SubsequentL } \\
\text { Ventricular CL }\end{array}$ & $\begin{array}{c}\text { Atrial CL } \\
\text { Predicted by } \\
\text { Preceding } \\
\text { Ventricular CL }\end{array}$ & $\begin{array}{c}\text { Indeterminate } \\
\text { Relationship }\end{array}$ \\
\hline Typical AVNRT (66) & $0(0 \%)$ & $55(83 \%)$ & $11(17 \%)$ \\
Atypical AVNRT (8) & $6(75 \%)$ & $0(0 \%)$ & $2(25 \%)$ \\
ORT (31) & $0(0 \%)$ & $27(87 \%)$ & $4(13 \%)$ \\
AT (21) & $18(86 \%)$ & $1(5 \%)$ & $2(9 \%)$ \\
\hline
\end{tabular}

ventricular CL for either AT or atypical AVNRT were $83 \%$, $100 \%, 100 \%$, and $95 \%$, respectively. The sensitivity, specificity, positive predictive value, and negative predictive value of the change in atrial CL being predicted by the preceding ventricular CL for either typical AVNRT or ORT were $85 \%$, $97 \%, 99 \%$, and $65 \%$, respectively.

\section{Discussion}

\section{Main Findings}

In the electrophysiology laboratory, many diagnostic aids are available for distinguishing AVNRT, ORT, and AT. However, most of the diagnostic tools that involve pacing maneuvers are of little or no value when episodes of PSVT are nonsustained or terminated by pacing. The findings of this study demonstrate that analysis of tachycardia CL variability may provide useful diagnostic information that is available even when episodes of PSVT are nonsustained. CL variability $\geq 15 \mathrm{msec}$ in magnitude occurs in $73 \%$ of PSVTs and is equally prevalent in AT, AVNRT, and ORT. When the change in atrial CL predicts the change in subsequent ventricular CL, this strongly favors either AT (Fig. 1A) or atypical AVNRT (Fig. 1B). When the change in atrial CL is predicted by the change in preceding ventricular CL, either typical AVNRT (Fig. 2A) or ORT (Fig. 2B) is the most likely mechanism. Therefore, analysis of the pattern of atrial and ventricular CLs provides a very simple diagnostic tool that may be helpful in narrowing down the differential diagnosis of a PSVT.

\section{Causes of Tachycardia Cycle Length Variability}

The atrioventricular node participates either actively or passively in all types of PSVT and the atrioventricular interval may vary depending on the preceding atrial CL and autonomic tone. A change in either anterograde or retrograde atrioventricular node conduction may result in tachycardia CL variability in AVNRT or ORT. In contrast, CL variability in AT is a result of either changes in the CL of the atrial reentrant or focal tachycardia, or changes in atrioventricular node conduction.

\section{Pattern of Changes in Atrial and Ventricular CLs}

AT originates from a focus or reentry circuit in the atrium and propagates to the ventricles through the atrioventricular node. Therefore, when there is CL variability in both the atrium and ventricle, changes in atrial CL would be expected to precede and predict the changes in ventricular CL. This pattern was observed in $86 \%$ of the ATs that displayed CL variability in this study. However, ventricular CL variability may be caused by changes in atrioventricular conduction 
Figure 2. Examples of a change in atrial $C L$ that is predicted by the change in preceding ventricular $C L$. Shown are surface leads I, II, III, and VI, and intracardiac recordings from the right atrium $(R A)$, His bundle (HIS), and right ventricle $(R V)$. A: Tachycardia $C L$ variability in ORT with an atrial $C L$ change $(\triangle A 1 A 2-A 2 A 3)$ of 44 msec. $\triangle A 1 A 2-V 1 V 2$ and $\triangle A 2 A 3-V 2 V 3$ are $50 \mathrm{msec}$ and $45 \mathrm{msec}$, respectively, and $\triangle A A-V V$ is $47.5 \mathrm{msec} . \triangle V 0 V 1-A 1 A 2$ and $\triangle V 1 V 2-A 2 A 3$ are $6 \mathrm{msec}$ and $6 \mathrm{msec}$, respectively, and $\triangle V V-A A$ is 6 msec. $\triangle V V-$ $A A$ is less than $\triangle A A-V V$, indicating that a change in atrial $C L$ is predicted by the change in preceding ventricular $C L$. B: Typical AVNRT with tachycardia $C L$ variability $(\triangle A 1 A 2-A 2 A 3)$ of $199 \mathrm{msec} . \triangle A 1 A 2$ $V 1 V 2$ and $\triangle A 2 A 3-V 2 V 3$ are $216 \mathrm{msec}$ and 124 msec, respectively, and $\triangle A A-V V$ is 170 msec. $\triangle V O V 1-A 1 A 2$ and $\triangle V 1 V 2-A 2 A 3$ are 2 msec and 17 msec, respectively, and $\triangle V V-A A$ is $9.5 \mathrm{msec}$.
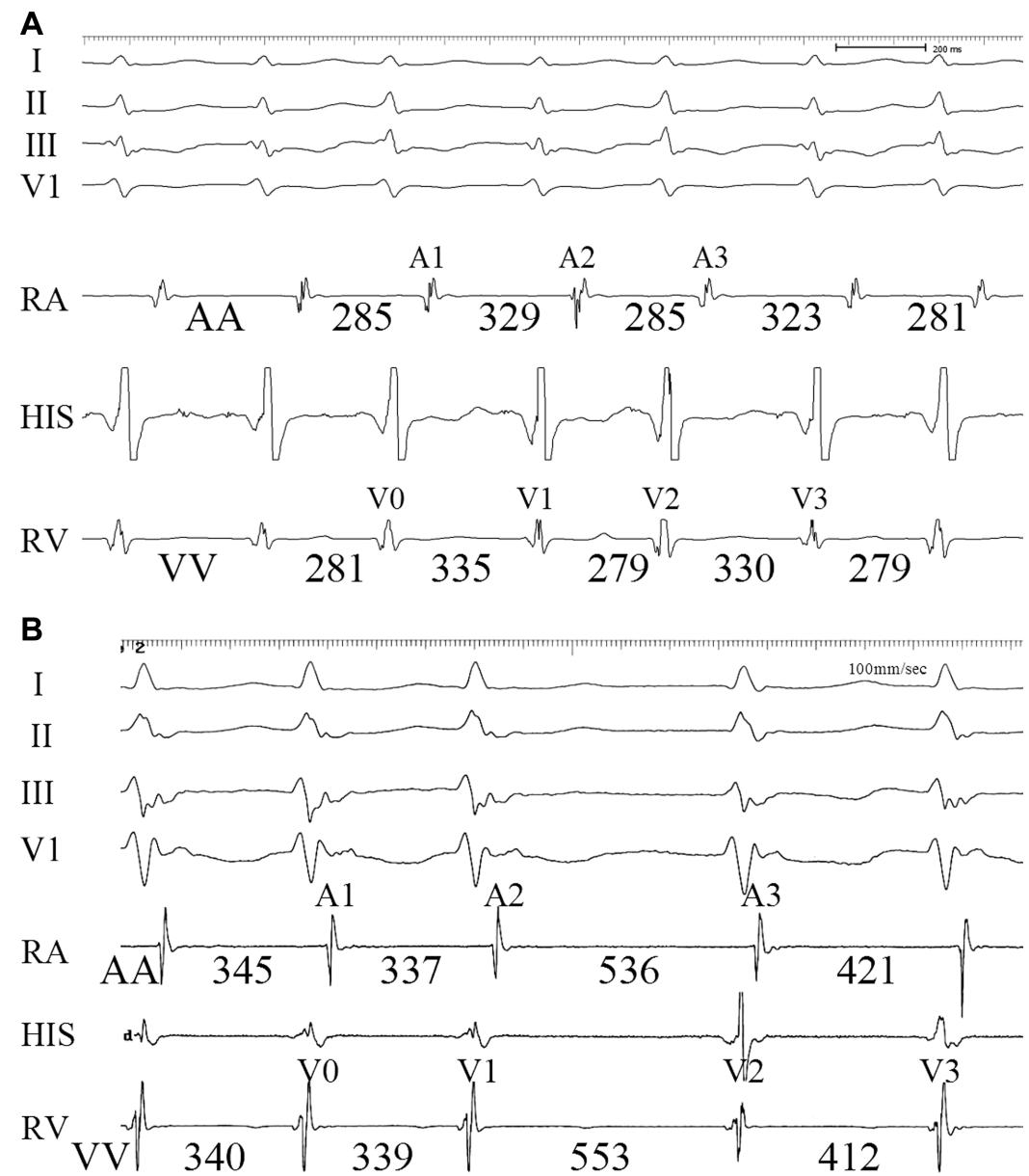

instead of changes in the CL of an AT, in which case ventricular CL variability might not be predicted by a prior change in atrial CL during an AT. Because there is no ventriculoatrial conduction during an AT, ventricular CL variability by itself would not be expected to result in atrial CL variability during an AT.

In contrast to AT, typical AVNRT and ORT generally have CL variability due to changes in anterograde atrioventricular nodal conduction. Because retrograde conduction through either a fast atrioventricular nodal pathway or an accessory pathway generally is much less variable than anterograde conduction through the atrioventricular node, the changes in ventricular CL that result from variability in anterograde atrioventricular nodal conduction would be expected to precede the subsequent changes in atrial CL. This explains why the change in atrial CL does not predict the change in subsequent ventricular CL in typical AVNRT and ORT.

In contrast, in atypical AVNRT, anterograde conduction occurs over the more stable fast atrioventricular node pathway and retrograde conduction is more subject to variability. This explains the finding that changes in atrial CL predicted the changes in subsequent ventricular $\mathrm{CL}$ in atypical AVNRT, as was the case in AT.
Figure 3. Example of an indeterminate relationship between the change in atrial and ventricular CL in typical AVNRT with a $\triangle A 1 A 2$ $A 2 A 3$ of $56 \mathrm{msec}$. The format is the same as in Figure 2. $\triangle A 1 A 2-V 1 V 2$ and $\triangle A 2 A 3-$ $V 2 V 3$ are 26 msec and $28 \mathrm{msec}$, respectively, and $\triangle A A-V V$ is $27 \mathrm{msec}$. $\triangle V O V 1-A 1 A 2$ and $\triangle V 1 V 2-A 2 A 3$ are $32 \mathrm{msec}$ and $30 \mathrm{msec}$, respectively, and $\triangle V V-A A$ is $31 \mathrm{msec}$. The relationship between atrial and ventricular $C L$ cannot be determined since the difference between $\triangle V V-A A$ and $\triangle A A-V V$ is less than 5 msec. The atrial $C L$ variability is possibly due to the presence of a premature atrial complex (A2), which does not change the following ventricular $C L$.

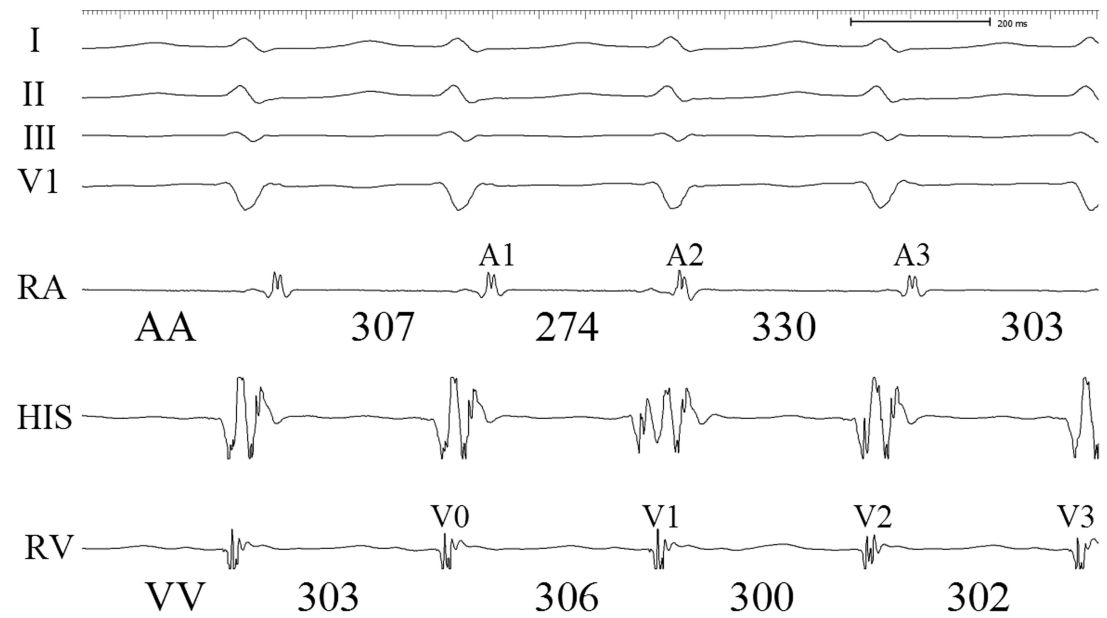


Figure 4. Example of atrial tachycardia with a change in atrial $C L$ that is predicted by the change in preceding ventricular $C L$. The atrial CL change ( $\triangle A 1 A 2-A 2 A 3)$ is $20 \mathrm{msec}$. The format is same as in Figure 2. $\triangle A 1 A 2-$ $V 1 V 2$ and $\triangle A 2 A 3-V 2 V 3$ are 16 msec and 6 msec, respectively, and $\triangle A A-V V$ is $11 \mathrm{msec}$. $\triangle V O V 1-A 1 A 2$ and $\triangle V 1 V 2-A 2 A 3$ are 2 msec and $4 \mathrm{msec}$, respectively, and $\triangle V V-A A$ is 3 msec. $\triangle A A-V V(11 \mathrm{msec})$ is greater than $\triangle V V-A A(3 \mathrm{msec})$, indicating that the change in atrial $C L$ is predicted by the change in preceding ventricular $C L$. The reverse relationship in this atrial tachycardia is caused by decremental $A V$ nodal conduction. $A V$ interval significantly increases from $110 \mathrm{msec}$ (A1-V1) to 126 msec (A2-V2) due to a shorter A1-A2 than the preceding atrial CL. This results in a much longer V1-V2 than A1-A2.

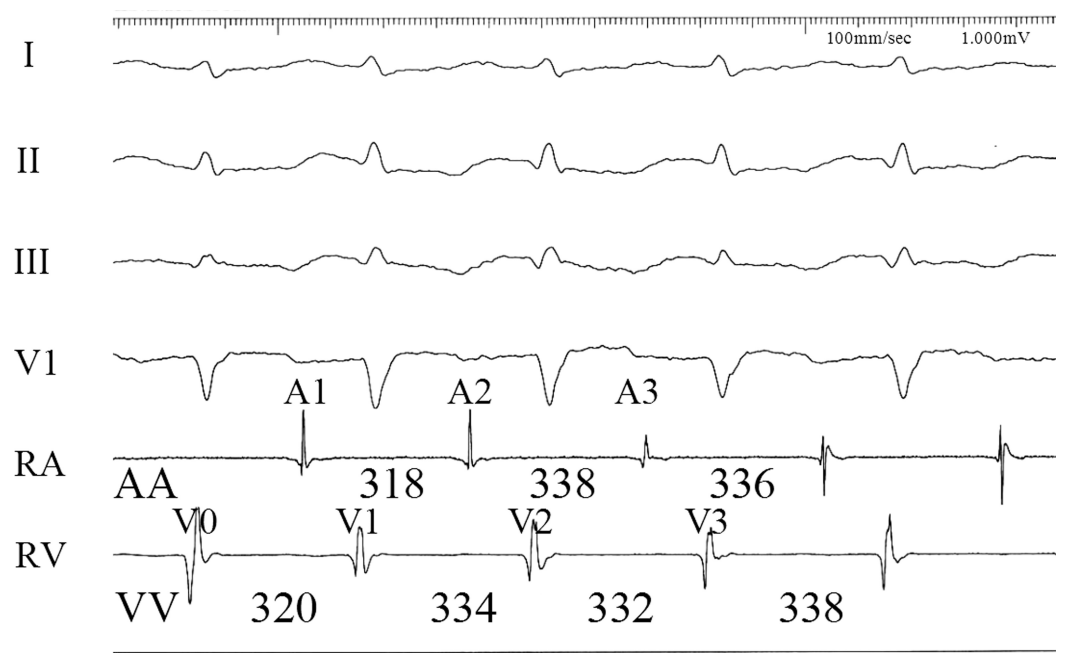

\section{Potential Pitfalls}

Although the relationship between changes in atrial and ventricular CL can be helpful in differentiating PSVT mechanisms, sometimes the relationship may be indeterminate. This was the case in $16 \%$ of PSVTs in this study that displayed CL variability. The indeterminate pattern of atrial and ventricular CL variability was observed more frequently in AVNRT and ORT. This might be caused by changes in both anterograde and retrograde conduction or the presence of premature complexes (Fig. 3). Because there is no ventriculoatrial conduction in AT, an indeterminate relationship was less frequently observed in AT. Analysis of tachycardia CL variability should be carefully performed and episodes with premature complexes should be avoided. Indeterminate relationship accounted for a low negative predictive value of the atrial CL predicted by preceding ventricular CL for diagnosing typical AVNRT and ORT.

One AT in this study had a change in atrial CL that was predicted by a change in the preceding ventricular CL (Fig. 4). This was explained by decremental anterograde atrioventricular nodal conduction, which resulted in a longer subsequent ventricular CL.

\section{Conclusion}

When the diagnosis of the PSVT mechanism is not feasible with pacing maneuvers, there are several tachycardia characteristics that may be helpful in differentiating AVNRT, ORT, and AT. These include the dependence of initiation on a critical atrial-His or atrioventricular interval, the relationship between the atrial and ventricular electrograms, the atrial activation sequence, and whether the tachycardia terminates with atrioventricular block. The results of this study demonstrate that if there is $\geq 15 \mathrm{msec}$ variability in tachycardia CL, this may provide additional information useful in diagnosing the mechanism of PSVT. If the change in atrial CL predicts the change in the subsequent ventricular CL, this is reliable evidence of either AT or atypical AVNRT. If the change in the atrial CL is predicted by the preceding ventricular CL, either typical AVNRT or ORT is likely to be the tachycardia mechanism.

\section{Referrences}

1. Benditt DG, Pritchett EL, Smith WM, Gallagher JJ: Ventriculoatrial intervals: Diagnostic use in paroxysmal supraventricular tachycardia. Ann Intern Med 1979;91:161-166.

2. Sung RJ, Waxman HL, Saksena S, Juma Z: Sequence of retrograde atrial activation in patients with dual atrioventricular nodal pathways. Circulation 1981;64:1059-1067.

3. Kerr CR, Gallagher JJ, German LD: Changes in ventriculoatrial intervals with bundle branch block aberration during reciprocating tachycardia in patients with accessory atrioventricular pathways. Circulation 1982;66:196-201.

4. Tracy CM, Swartz JF, Fletcher RD, Hoops HG, Solomon AJ, Karasik PE, Mukherjee D: Radiofrequency catheter ablation of ectopic atrial tachycardia using paced activation sequence mapping. J Am Coll Cardiol 1993;21:910-917.

5. Kay GN, Chong F, Epstein AE, Dailey SM, Plumb VJ: Radiofrequency ablation for treatment of primary atrial tachycardias. J Am Coll Cardiol 1993;21:901-909.

6. Kadish AH, Morady F: The response of paroxysmal supraventricular tachycardia to overdrive atrial and ventricular pacing: Can it help determine the tachycardia mechanism? J Cardiovasc Electrophysiol 1993;4:239-252.

7. Hirao K, Otomo K, Wang X, Beckman KJ, McClelland JH, Widman L, Gonzalez MD, Arruda M, Nakagawa H, Lazzara R, Jackman WM: ParaHisian pacing. A new method for differentiating retrograde conduction over an accessory AV pathway from conduction over the AV node. Circulation 1996;94:1027-1035.

8. Knight BP, Zivin A, Souza J, Flemming M, Pelosi F, Goyal R, Man C, Strickberger SA, Morady F: A technique for the rapid diagnosis of atrial tachycardia in the electrophysiology laboratory. J Am Coll Cardiol 1999;33:775-781.

9. Knight BP, Ebinger M, Oral H, Kim MH, Sticherling C, Pelosi F Michaud GF, Strickberger SA, Morady F: Diagnostic value of tachycardia features and pacing maneuvers during paroxysmal supraventricular tachycardia. J Am Coll Cardiol 2000;36:574582.

10. Michaud GF, Tada H, Chough S, Baker R, Wasmer K, Sticherling C, Oral H, Pelosi F Jr, Knight BP, Strickberger SA, Morady F: Differentiation of atypical atrioventricular node re-entrant tachycardia from orthodromic reciprocating tachycardia using a septal accessory pathway by the response to ventricular pacing. J Am Coll Cardiol 2001;38:11631167.

11. Josephson M. Supraventricular tachycardia. In: Josephson M, ed. Clinical Cardiac Electrophysiology. Second edition. Malvern, PA: Lea \& Febiger, 1993, pp. 181-274.

12. Lockwood D, Otomo K, Wang Z, Forresti S, Nakagawa H, Beckman K, Scherlag BJ, Patterson E, Lazarra R, Jackman WM: Electrophysiologic characteristics of atrioventricular nodel reentrant tachycardia: Implications for the reentrant circuits. In: DP Zipes, J Jalife, eds. Cardiac Electrophysiology: From Cell to Bedside. Philadelphia: W.B. Saunders Company, 2004, pp. 537-557. 
13. Leitch J, Klein GJ, Yee R, Murdock C: Invasive electrophysiologic evaluation of patients with supraventricular tachycardia. Cardiol Clin 1990;8:465-477.

14. Josephson ME, Seides SE, Batsford WB, Caracta AR, Damato AN, Kastor JA: The effects of carotid sinus pressure in re-entrant paroxysmal supraventricular tachycardia. Am Heart J 1974;88:694-697.
15. Munkenbeck FC, Bump TE, Arzbaecher RC: Differentiation of sinus tachycardia from paroxysmal 1:1 tachycardias using single late diastolic atrial extrastimuli. Pacing Clin Electrophysiol 1986;9:53-64.

16. Ross DL, Uther JB: Diagnosis of concealed accessory pathways in supraventricular tachycardia. Pacing Clin Electrophysiol 1984;7:10691085 . 